\title{
TERTIARY SYPHILIS OF THE LUNG AND ITS DIAGNOSIS
}

\author{
BY \\ A. D. MORGAN, W. E. LLOYD, AND SIR CLEMENT PRICE-THOMAS \\ From the Westminster Hospital, London
}

(RECEIVED FOR PUBLICATION OCTOBER 17, 1951)

Acquired syphilis of the lung is a rare condition, but the diagnostic criteria are so variable that it is difficult to assess the degree of rarity. To quote Lord (1925), " the diagnosis cannot be made with assurance during life, and is often uncertain at the post-mortem." Lord himself found no proved cases in the course of 4,705 routine necropsies at the Massachusetts General Hospital, although three were suggestive; on the other hand, Symmers (1916) records the diagnosis in 12 out of 4,880 necropsies at the Bellevue Hospital, New York.

In spite of its rarity there is no lack of case records of acquired pulmonary syphilis, and these have been adequately reviewed (Karshner and Karshner, 1920 ; Carrera, 1920; Howard, 1924; McIntyre, 1931); and fresh cases are published at the rate of half a dozen every year. But again there is a distinct variation in the reserve with which the reviewers accept the diagnosis. Howard, writing in 1924, found 200 cases in the literature, but McIntyre, seven years later, could accept only 97 between the years 1854 and 1920; of these, roughly half were diagnosed at necropsy, and the remainder on radiological evidence or by response to antisyphilitic treatment.

In the last century the difficulty lay in differentiating pulmonary syphilis from tuberculosis, and, before the discovery of the tubercle bacillus by Koch in 1882, there is little doubt that many cases diagnosed as pulmonary syphilis were in fact tuberculous. But since the demonstration of the Spirochaeta pallida by Schaudinn in 1905, and the introduction of serological techniques, it has been possible to diagnose pulmonary syphilis with a greater degree of confidence, always bearing in mind that it is no rarity for a tuberculous patient to have a positive Wassermann reaction as well. We present our case because it illustrates the difficulties of clinical diagnosis, and because the fresh pneumonectomy specimen gives a clearer patho- logical picture than is usually offered in published articles on this condition.

\section{CASE History}

C.H.B., aged 64, a retired fruit grower, was admitted to the Royal Masonic Hospital, London, on August 3, 1948, for investigation of right-sided upper abdominal pain of four months' duration. A diagnosis of gall-bladder disease was made, and on August 6 a large distended gall-bladder containing numerous pigment stones was removed by Mr. Eric Crook. Some collapse of the right lower lobe occurred on the following day but soon improved. On August 13 the patient complained of a sudden attack of pain in the right lower chest suggestive of a pulmonary infarct. Radiological examination revealed an opacity in the right lower lobe and also in the left upper lobe. The right lower lobe opacity cleared, but that in the left upper zone remained. When first seen by one of us (W.E.L.) on September 2 breath sounds were found to be diminished in the left upper lobe and some medium rales were present. Sputum examination proved negative for tubercle bacilli. No significant changes were found on bronchoscopic examination by Mr. Myles Formby. The patient's general condition continued to be satisfactory, but as the opacity in the left upper lobe persisted the possibility of a malignant disease was considered before the patient left hospital on October 9. Subsequent radiographs revealed the same abnormal appearances in the left upper lobe, and the patient was admitted to Westminster Hospital on January 25,1949 , for further investigations. By that time he complained of an unproductive cough, and he said he had become more short of breath than before his operation. Fig. 1 shows the radiological appearances at that time. The repeated sputum examinations were negative for tubercle bacilli and also for malignant cells. Wassermann and Kahn tests were not included in the investigations. Bronchoscopy again did not reveal any significant abnormality and a thoracotomy was advised. After opening the chest a hard mass was felt in the left upper lobe and a smaller mass in the lower lobe. Pneumonectomy was performed on February 9, and after the operation the patient made a good recovery and was able to leave hospital on March 4. 


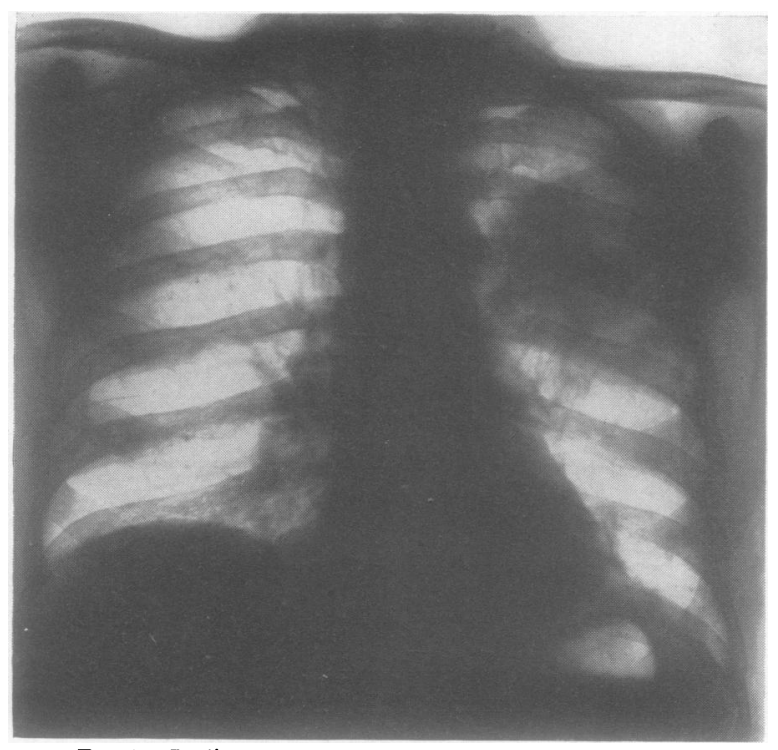

FIG. 1.-Radiograph of chest showing lesion in left upper lobe.

Before leaving hospital the Wassermann, Kahn, and Laughlen tests were all found to be strongly positive.

\section{Pathological RePort}

Naked-eye Examination.-The upper lobe of the left lung was somewhat contracted, and overlying its anterolateral segment was a dense, white fibrous plaque, $4 \mathrm{~cm}$. in diameter and $1 \mathrm{~cm}$. thick, and more properly described as a pleural scar than a simple adhesion. Underlying this was an irregularly shaped area of consolidation, $8 \times 6 \mathrm{~cm}$., and occupying the peripheral part of the lung to a depth of $3.5 \mathrm{~cm}$. below the pleural surface.

On section (Fig. 2) this was seen to be composed of an agglomeration of light grey or creamy yellow nodules, the former being rubbery, the latter of cheesy consistency. At least 15 of these were seen in the plane of section, the largest being $3 \mathrm{~cm}$. in diameter, the smallest $3 \mathrm{~mm}$. The larger ones had a rather indistinct outline, but the majority had a well-defined serpiginous margin and appeared to be encapsulated, separated from each other by strands of fibrotic lung rich in carbon pigment.

At the first division of the left main bronchus, several centimetres distant from the main lesion, were two older calcified nodules. In the anterior basic segment of the lower lobe was a smaller but similar lesion in the form of two nodules, each $1 \mathrm{~cm}$. in diameter, lying a few millimetres below the pleura (Fig. 3).

Histology.-Microscopically the nodules had the characters of typical gummata. Throughout the caseous areas it was just possible, in haematoxylin-eosin-stained preparations, to trace the pattern of necrotic pulmonary alveoli and blood vessels (Fig. 4). This pattern could be brought up much more clearly by Weigert's staining, which showed a considerable amount of residual elastic tissue in the necrotic walls of alveoli and blood vessels, although fragmented and reduced in amount (Fig. 5) when compared with the normal lung. This method revealed large arteries and veins buried in the gummata, with collapsed necrotic walls and lumina (up to 1.5 $\mathrm{mm}$. in diameter) filled with caseous material. The periphery of the well-circumscribed gummata was also characteristic, with a sharp transition from caseation to fibrosis, serpiginous in outline, and fibroblastic or collagenous according to its age (Fig. 6). In the centre $\vec{\circ}$ of the caseous areas a few showed slight powdery calcification, while towards the periphery others contained small amounts of carbon pigment. None had the microscopic characters of tuberculosis; endothelioid cell proliferation was absent, multinucleated giant cells were not a feature, and Ziehl-Neelsen preparations ? failed to show the presence of tubercle bacilli. Gummata of more recent origin contained large amounts of nuclear fragments (Fig. 7); these were not sharply circumscribed, and at the periphery could be seen ulcerating into bronchioles (Fig. 8). The intervening lung showed fibrosis of two main types: (1) interstitial fibrosis of the alveolar walls, producing a network of collagen enclosing air spaces which were lined by a low cubical epithelium (Fig. 9) and contained serous fluid and groups of lipoidfilled macrophages (Fig. 10), the elastic tissue in the fibrous network being generally reduced and fragmented; (2) patches of dense sclerosis (Fig. 11), quite airless but rich in blood vessels, sometimes with the residual elastic tissue forming a coarse fibrillar network, suggesting a true proliferation, and not merely an apparent increase due to concentration of elastic fibrils in the process of scarring with retraction (Fig. 12).

Between these two types of fibrosis lay all shades of transition (Fig. 13). The medium-sized vessels showed severe syphilitic arteritis, with gross proliferative endarteritis causing great narrowing of the lumen, and roundcelled infiltration of the media (Fig. 14). In addition to the lymphoid nodules which accompany most forms of pulmonary fibrosis there were scattered foci of plasma cells and lymphocytes, referred to by some authorities as " miliary gummata" (Fig. 15). At the periphery of the diseased area lay ill-defined patches of recent active pneumonia, the alveoli being filled with a serous exudate containing macrophages with a more or less foamy cytoplasm (Fig. 16), while the alveolar walls showed quite definite necrosis with destruction of elastic tissue (Fig. 17).

Serial sections of a number of blocks were stained by Levaditi's technique and a careful search for spirochaetes was made, with negative results.

\section{Problems of Diagnosis}

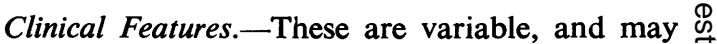
be absent (Powell and Hartley, 1911), but in general the symptoms and signs are those of any chronic pulmonary lesion. Considerably less toxic in its early stages than tuberculosis (the disease which in other respects it most closely simulates) the syphilitic process is usually far advanced before there is any appreciable change in the patient's health (Lisser, 1918). This comparatively good 


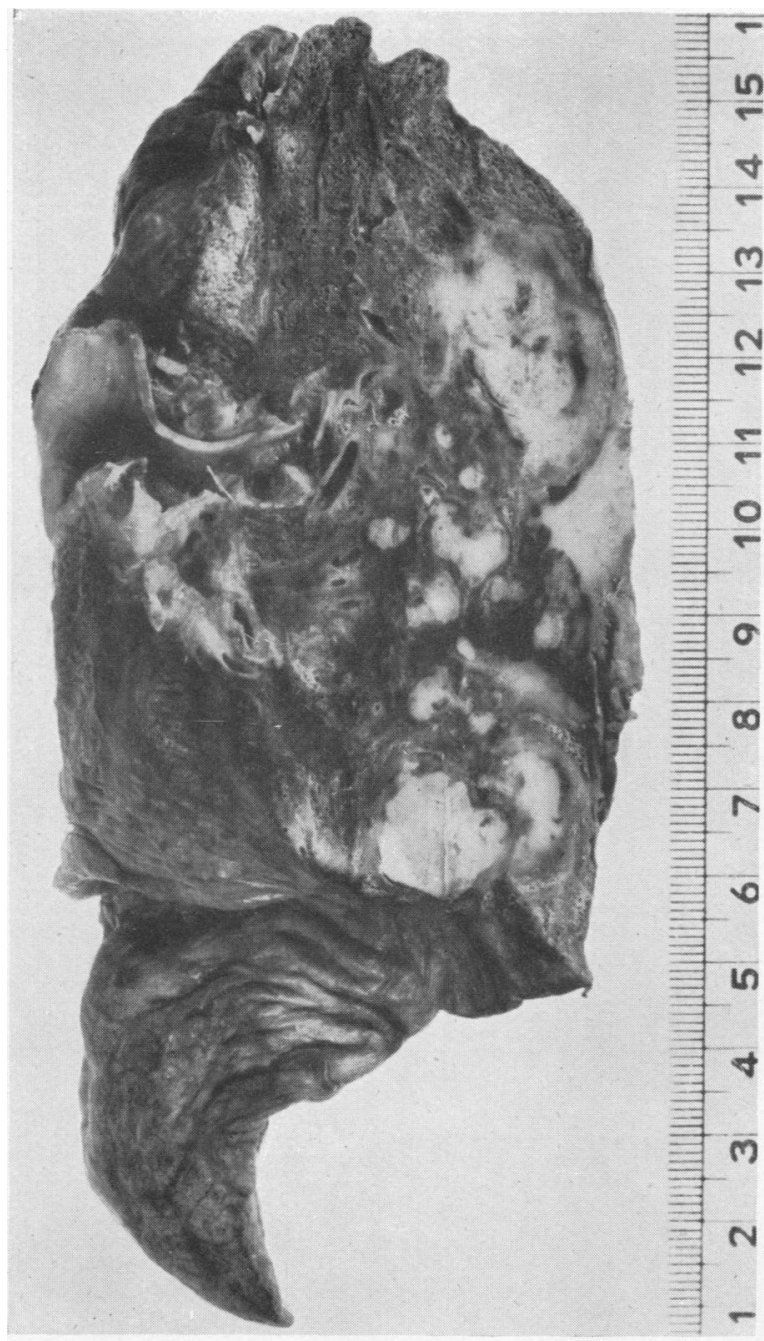

FIG. 2.-Cut surface of lung showing multiple gummata (actual size)

health with absence of fever, judged in the light of the physical signs and radiological appearances, is considered by several authors to be one of the most important criteria in distinguishing the disease from tuberculosis.

Karshner and Karshner, in their analysis of 120 cases, found cough by far the commonest symptom (present in $88 \%$ ) with a variable muco-purulent sputum $(71 \%)$, liable to be foul if the condition is complicated by bronchiectasis. Haemoptysis was recorded in $37 \%$, dyspnoea in $33 \%$. Less frequently chest pains and hoarseness are mentioned, and in the later stages there is a variable pyrexia and loss of weight.

Physical signs may be few and absent. In our own case the comparative paucity of physical signs in relation to the extent of the lesion is noteworthy. Karshner and Karshner found rales the most frequently recorded sign; others mention impaired chest movement on the affected side, dullness to percussion, diminished breath sounds, bronchial breathing, decreased vocal resonance, and occasionally pleural friction. A unilateral distribution, with little tendency to spread to the opposite lung, was considered by Tylecote (1927) to be suggestive, but this is at variance with the review of Howard, which states that in nearly half the recorded cases the lesion is bilateral.

Other luetic stigmata, such as aortic incompetence or aneurysm, Argyll-Robertson pupils, and absent knee-jerks, should be looked for, but their importance need not be over-stressed.

FIG. 3. -Subpleural lesion in lower lobe $(\times 8 / 9)$.

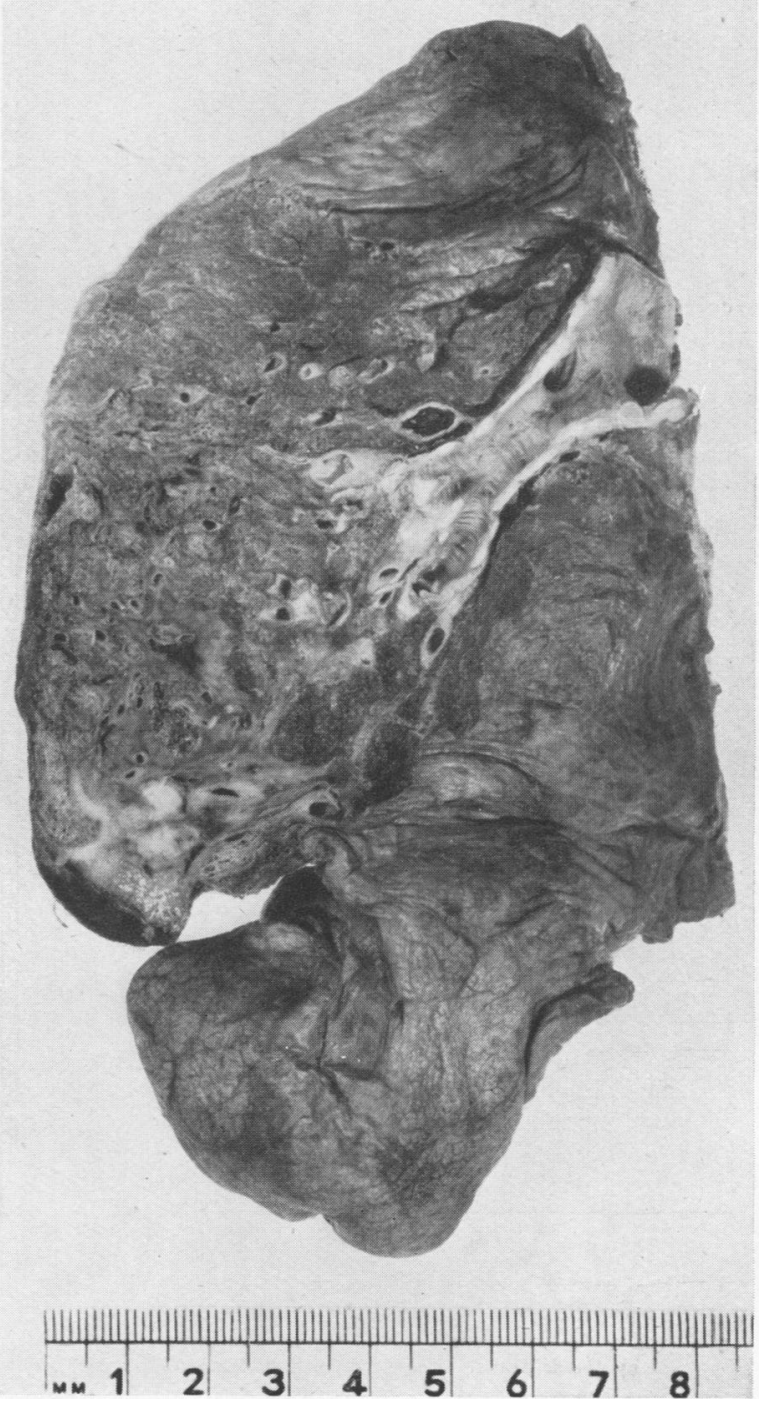




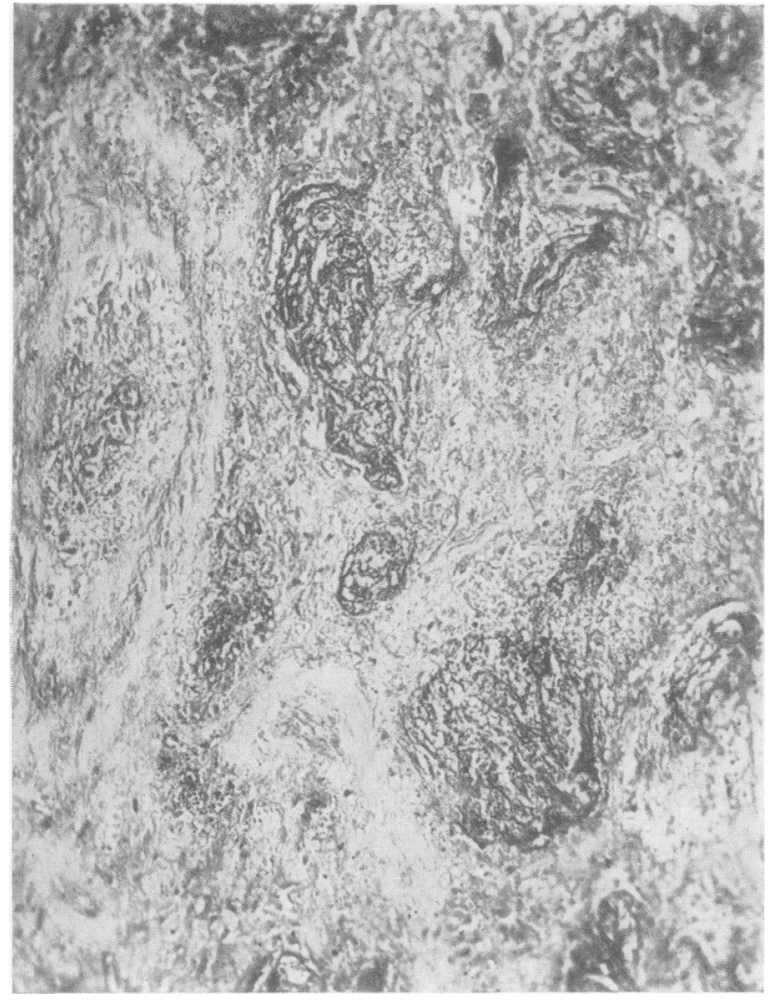

FIG. 4

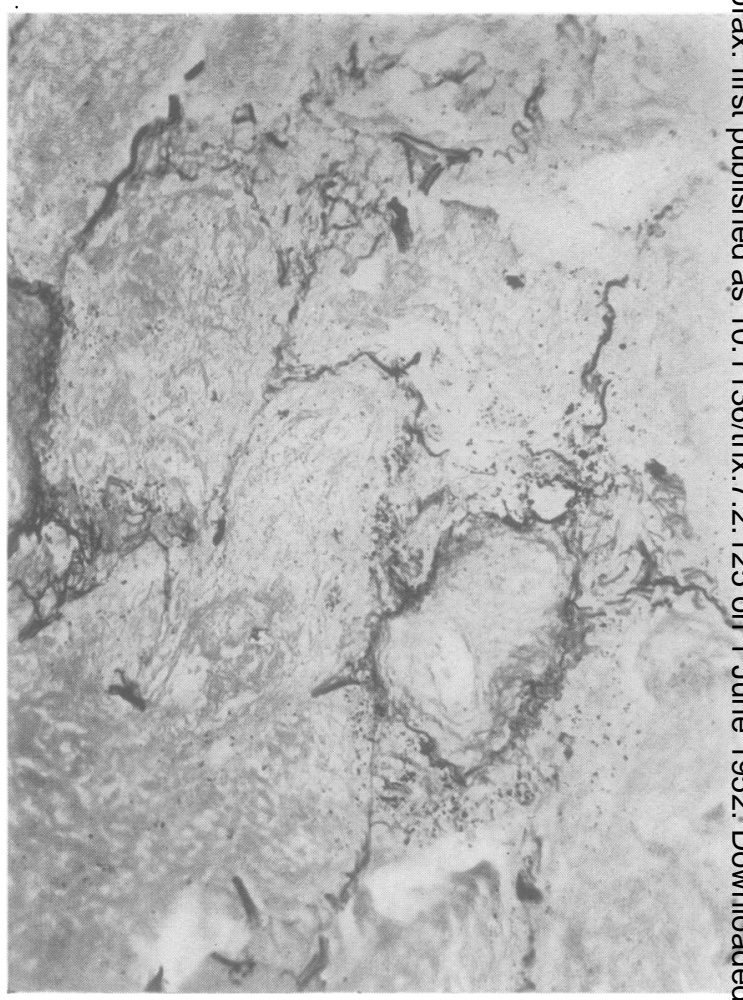

FIG. 5

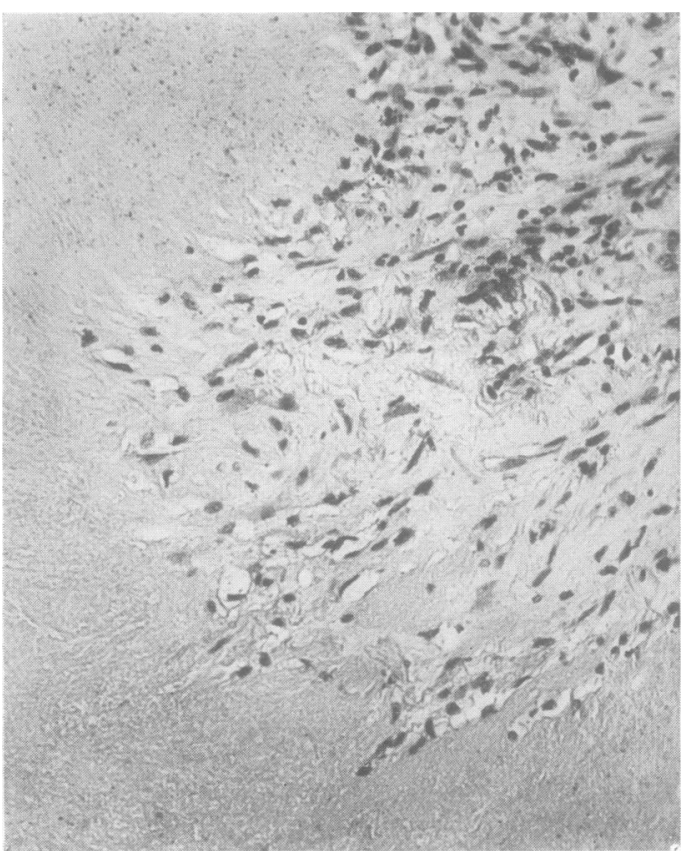

FIG. 6

FIG. 4.-Centre of gumma showing vague outline of blood vessels and alveoli. Haematoxylin and eosin, $\times 120$.

FIG 5.-Centre of gumma showing retention of alveoiar pattern by elastic fibrils. Weigert's elastic stain, $\times 120$.

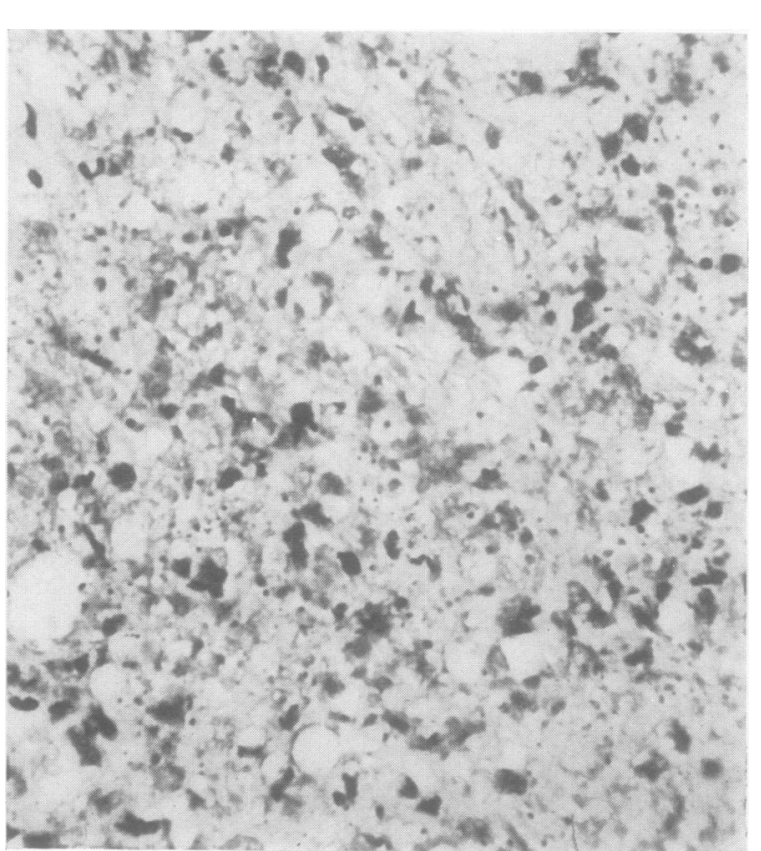

FIG. 7

FIG. 6.-Serpiginous margin of gumma showing sharp transition from caseation to fibrosis. Haematoxylin and eosin, $\times 150$.

FIG. 7.-Wore recent gumma containing nuclear fragments. Haematoxylin and eosin, $\times 450$. 


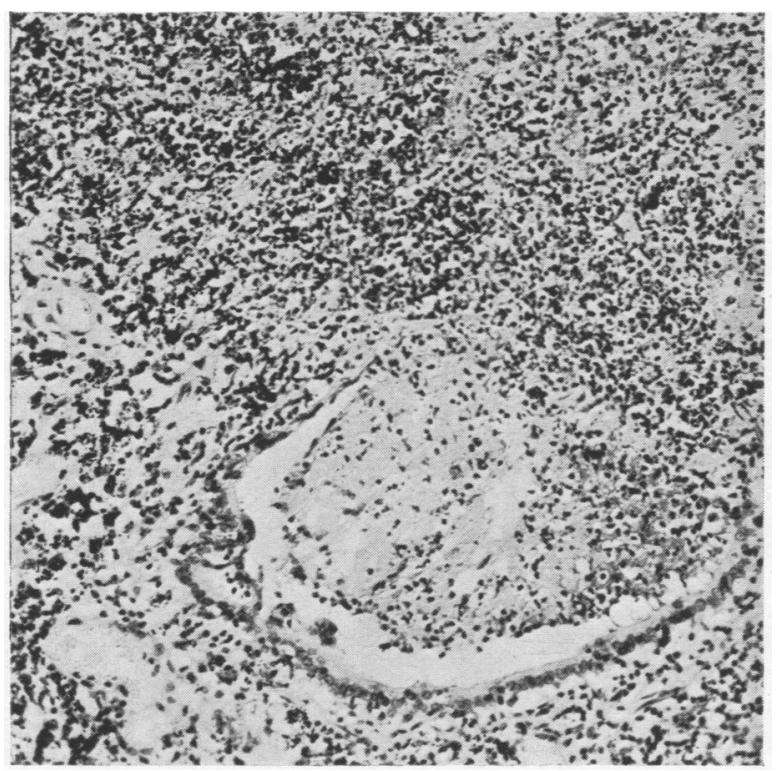

FIG. 8

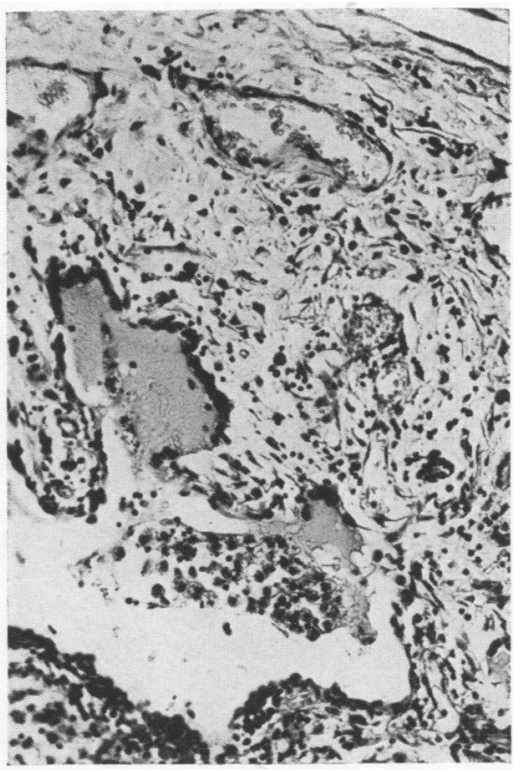

Fig. 9

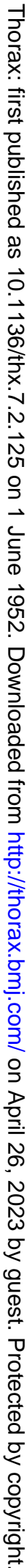

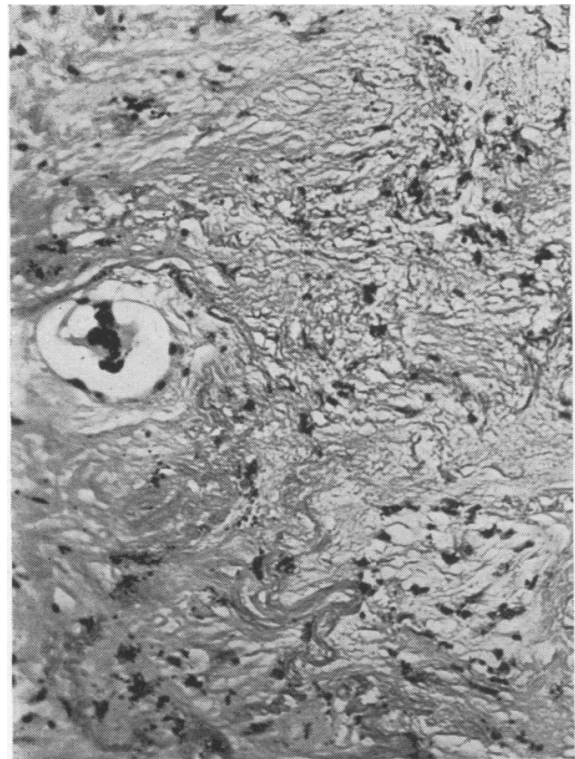

Fig. 11

FiG. 8.-Edge of gummatous process ulcerating into a bronchiole. Haematoxylin and eosin, $\times 120$

Fig. 9.-Interstitial fibrosis producing cubical metaplasia of alveolar epithelium. Haematoxylin and eosin, $\times 120$.

Fig. 10. - Interstitial fibrosis with fluid and lipoidcontaining macrophages in alveolar spaces. Haematoxylin and eosin, $\times 140$.

Fig. 11.-A rea of dense sclerosis, a structure!ess fibrous mass. Haematoxylin and eosin, $\times$ fibrous
$\times \quad 14$

Fig. 12.-Same area as Fig. 10, showing proliferation of elastic tissue. Weigert's elastic stain,

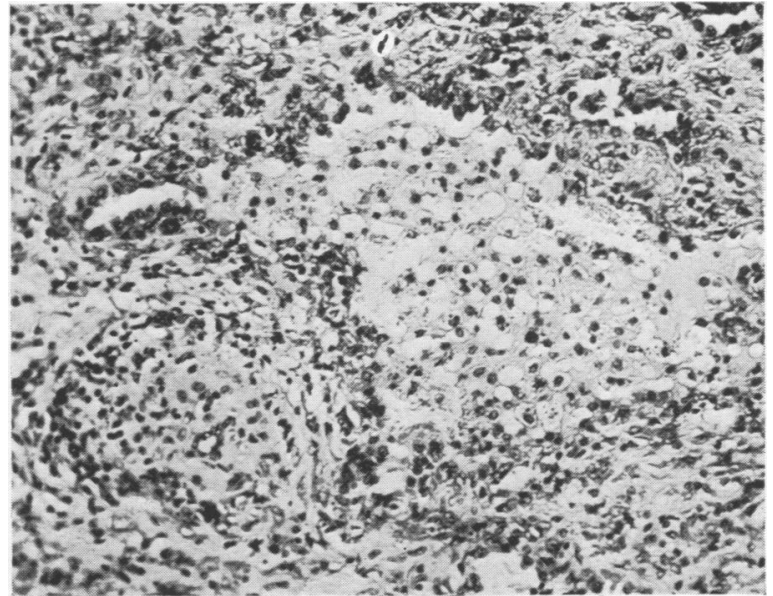

FIG. 10

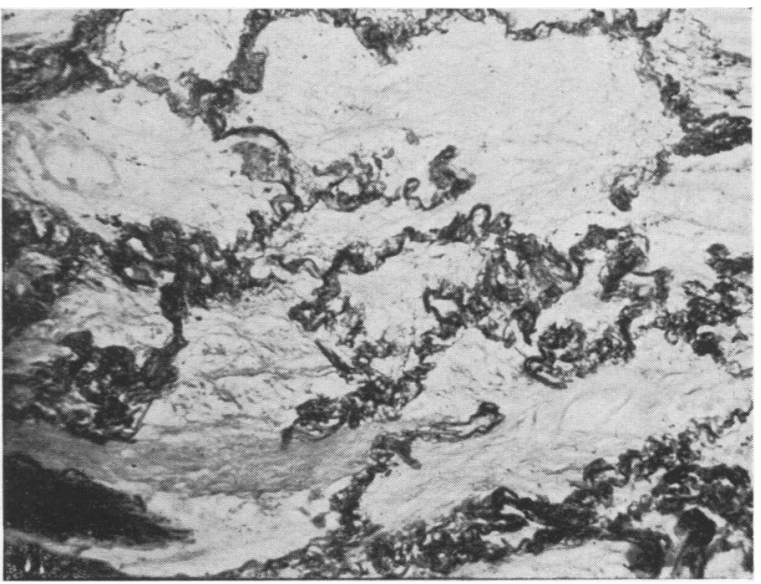

FIG. !2 


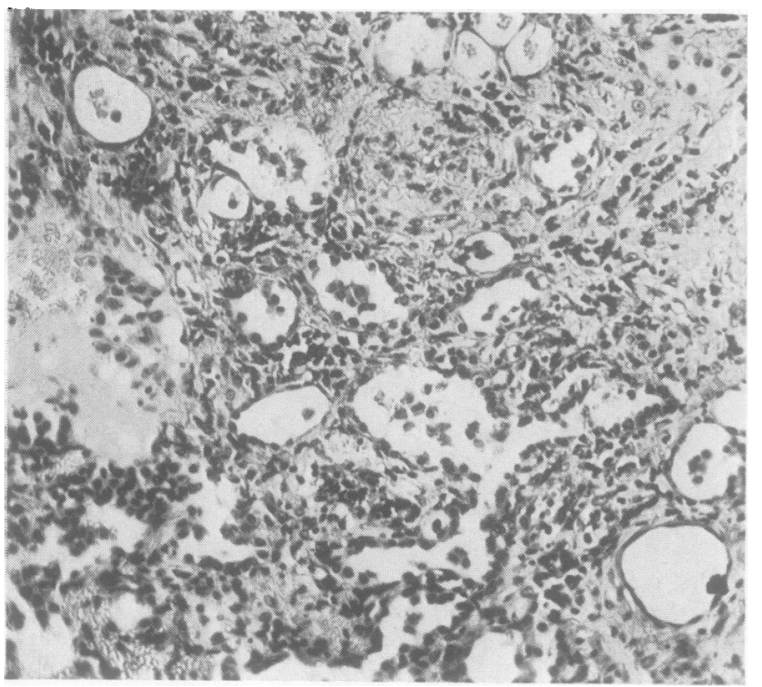

Fig. 13

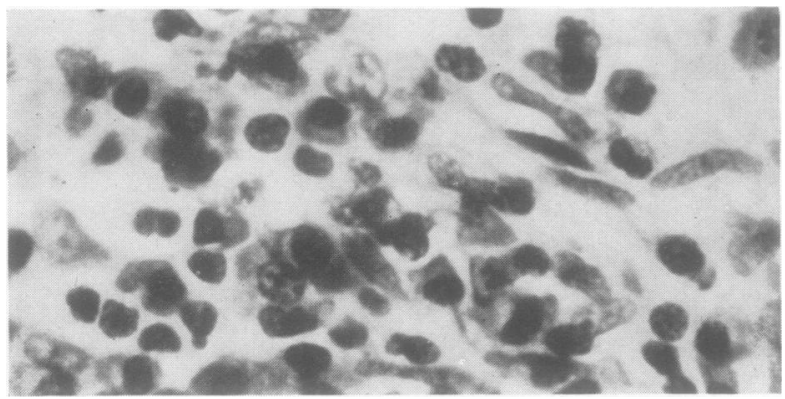

FIG. 15

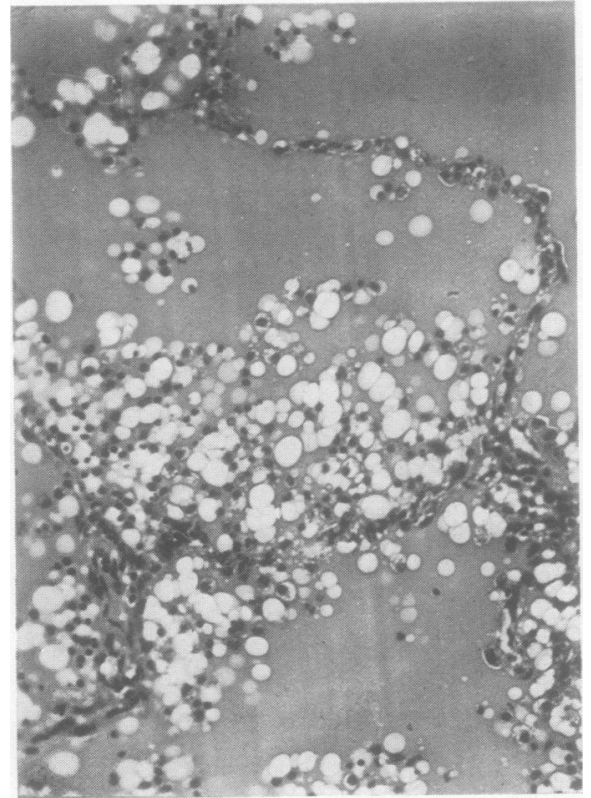

FIG. 16

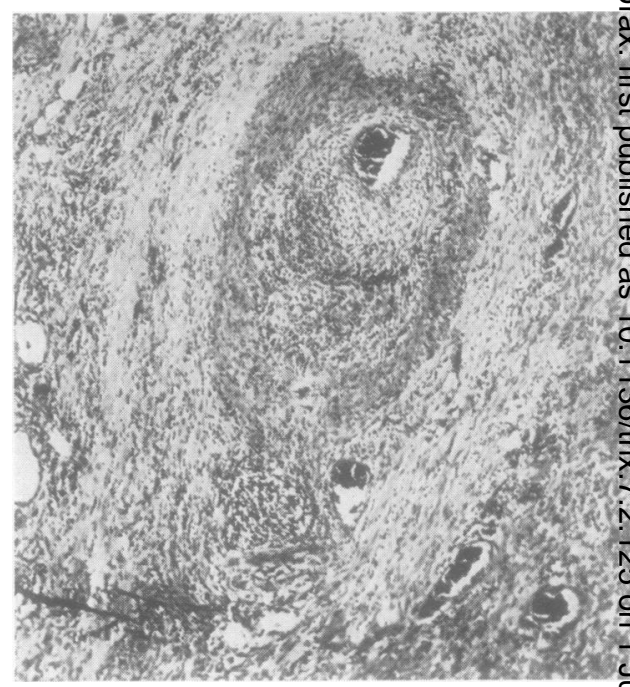

FIG. 14

言

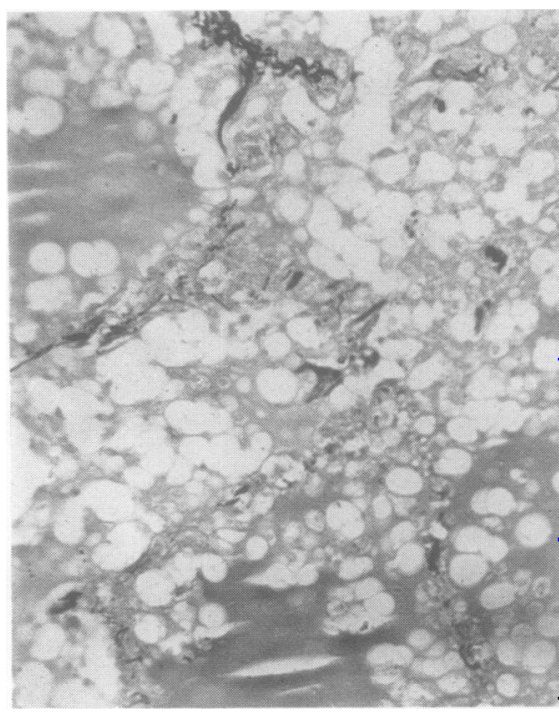

FIG. 17

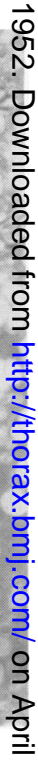

ก

FIG. 13-Transition between interstitial fibrosis and dense sclerosis. Haematoxylin and eosin, $\times 120$

FIG. 14.-Syphilitic arteritis with gross narrowing of lumen. Haematoxylin and eosin, $\times 40$.

FIG. 15-Plasma cells and lymphocytes in a miliary gumma. Haematoxylin and eosin,
$\times 450$.

FIG. 16.-Peripheral zone of pneumonia with a serous exudate in the alveoli. Haematoxylin and eosin, $\times 140$.

Fig. 17.-Same area as Fig. 15, showing destruction of elastic tissue in alveolar walls Weigert's elastic stain, $\times 140$. 
Types of Lesion.-The pathological accounts of syphilis of the lung, apart from the "white lung" of congenital syphilis, and the ulcerative lesions of trachea and bronchi in the adult, are variable, particularly as regards nomenclature, but broadly speaking two types of lesion emerge, the gummatous and the fibrotic. Stanley (1911) recognized a fairly rapid acute interstitial infiltration occurring early in tertiary syphilis, which he regarded as a separate entity and which he termed "syphilitic pneumonia," but Howard and several others are sceptical of this. Pearson and De Navasquez (1938) applied the same term to a gelatinous type of pneumonia causing necrosis of the alveolar walls, in view of the presence of coarse gummata in the opposite lung. Pneumonic infiltration surrounding gummatous lesions is mentioned below.

Fibrosis appears to be of two varieties. The " early diffuse fibrosis" of Stanley does not differ from the "chronic interstitial pneumonia" of Howard, and is essentially a post-inflammatory interstitial fibrosis causing thickening of the alveolar walls. Stanley's "dense sclerosis" is regarded by Howard as a more advanced stage of the above, and in this connexion it is worth noting that our own case showed all degrees of transition from early interstitial fibrosis to dense scarring. On the other hand, dense sclerosis may be merely the end-result of gummata which have undergone absorption. The " pulmo lobatum " of healed sclerogummatous syphilis is well illustrated in an article by De Navasquez (1942). But in the absence of gummata, fibrosis, even when accompanied by endarteritis and plasma cell infiltration, cannot be diagnosed with certainty as a specific lesion, however suggestive the picture may be as a whole.

It is the gumma, therefore, that is the only specific histological criterion in the diagnosis of pulmonary syphilis. With the improvement of diagnostic and therapeutic measures, the gumma is no longer a commonplace in the post-mortem room or the operating theatre, but its histological features are sufficiently characteristic to enable a pathologist to differentiate it from caseous tuberculosis. Among the more important points one might note: $(a)$ the serpiginous margin, with the abrupt transition from necrosis to fibrosis; $(b)$ the absence of proliferation of endothelioid cells at the periphery; $(c)$ the retention of tissue pattern in the necrotic area (especially of the elastic tissue) with less tendency to caseation. Additional criteria are the presence of endarteritis and plasma cells, and the relative paucity of giant cells, anthracosis, and calcification. The absence of tubercle bacilli in stained section means little, as the difficulty of demonstrating the organism in certain forms of caseous tuberculosis is well known. On the other hand, the presence of acid-alcohol-fast bacilli, while not absolutely conclusive, should make one hesitate to diagnose such a rare lesion as pulmonary syphilis. In either case guinea-pig inoculation tests should be carried out before tuberculosis is finally excluded.

Gummata are usually multiple, and may occur in any part of either lung, usually accompanied by interstitial fibrosis, dense sclerosis, and localized pneumonia, as in our own case. The term " sclerogummatous" as applied to this form is fairly comprehensive and is to be preferred to "syphilitic phthisis" which Howard used to describe the same picture. Good examples are recorded by Pearson and De Navasquez (1938) and by Wilson (1946). Cavitation of a gumma is a rare complication (e.g., $\mathrm{Hu}$, Frazier, and Hsieh, 1939), but bronchiectatic cavities are not an uncommon sequel to fibrosis, and Finochietto and Halperin (1941) and Aguilar and Bancalari (1941) performed lobectomy on this account.

The demonstration of spirochaetes is too difficult to be a useful criterion. As Hartung and Freedman (1932) point out, spirochaetes have only rarely been found in tertiary syphilis in general, so it is not to be expscted that they will be found in gummata of the lungs. They were, however, demonstrated by Koch (1907), Schmorl (1907), Keilty (1916), Warthin (1917), and more recently Wilson, using Krajian's technique, was successful. The most painstaking scrutiny of serial sections is required, and in the majority of recorded attempts the results were negative. Lord reminds us that non-syphilitic spirochaetes may also be found in lung tissue, and in this connexion Howard warns against diagnosing syphilis from the finding of spirochaetes in the sputum, as these may be saprophytic, especially in the presence of bronchiectasis.

Dense pleural scars are referred to by several authors and appear to be a characteristic feature of the sclerogummatous form. Since gummata are commonly sub-pleural, it may be that these thick white scars represent the end-stage of cicatrization.

Syphilitic lesions of the lungs are never early, according to Dieulafoy (1910), the average interval between the primary infection and the development of pulmonary lesions being 10 to 11 years, exceptionally one to 25 years. One might expect to find stigmata of the disease in other organs. In Howard's series other gummata were found in the liver, spleen, testes, subcutaneous tissues, nasal septum, tibia, ribs, and sternum. Pearson and De Navasquez point out that aortitis is a frequent accompaniment 
of syphilis of the lung, and quote anatomical evidence to suggest that pulmonary lesions result from extension of the infection from the mediastinum.

Radiological Appearances.-As with most other aspects of pulmonary syphilis, opinion on the value of radiographs in diagnosis varies, even making allowances for improved technique over the last 30 years. Howard dismissed the radiological appearances as not pathognomonic and did not list them among his diagnostic criteria except in conjunction with the therapeutic test. Hartung and Freedman were of similar persuasion, and as recently as 1949 Findlay, Lehman, and Rottenberg echoed these views. On the other hand, Watkins $(1917,1921)$ was sufficiently confident of his criteria to diagnose, out of 6,500 routine radiological examinations for suspected diseases of the heart or lungs, no less than 172 , i.e., $2.6 \%$ of the total, as pulmonary syphilis.

In the differentiation of syphilis from tuberculosis, Golden (1921) considered the following three points of importance : (1) the tendency of syphilis to attack the middle and lower lobes, especially in the hilar region; (2) its liability to spread from the hilus to the periphery ; and (3) its disposition to cause dense pleural scarring.

Robinson (1935), elaborating the conclusions of earlier investigators, recognized three types of radiological picture:

" (1) A generalized thickening of all the bronchial markings, studded with minute 'knobby' enlargements, radiating out from the hilum into one or both lung fields, and producing the characteristic fan-shaped effect, a diffuse interstitial fibrosis of the bronchial tree. If bilateral, this lesion may be confused with the infiltrative type of metastatic malignancy. If unilateral, primary bronchogenic carcinoma of the infiltrating type must be excluded. The process may be confined to comparatively small areas, found more especially in the hilus of the lung.

"(2) Gummas, miliary or multiple, or solitary discrete masses several $\mathrm{cm}$. in diameter, appearing as nodular areas of increased density usually near the hilus, or even in the periphery of the lung field. In the early stage of development of the latter, a delimiting zone of pneumonitis is formed about them, which is replaced in later stages by a fibrous connective tissue capsule. They may become necrosed, demonstrated by an area of rarefaction in the central portion of the nodule. Instead of necrosis, fibrosis may occur. In the early stage of the solitary type, especially if situated in the periphery of the lung, the condition may be confused with a lobular tuberculosis or abscess formation. In the later stage of encapsulation, and located near the hilus, it resembles a primary malignant tumour. The miliary gummata may be mistaken for metastatic malignancy.

" (3) The diffuse lobar form, which is occasionally described as a distinct entity, should not be classed as such because the lesion itself is probably in the primary bronchus, and the picture is one of secondary massive atelectasis resulting from a bronchostenosis." o

To the above might be added the observation that on rare occasions bronchiectasis has been $\vec{\omega}$ diagnosed without it being realized that the underlying cause was sclerogummatous syphilis.

In the most recent edition of their work Shanks and Kerley (Twining and Kerley, 1951) recognize $\stackrel{N}{\sim}$ four types of picture. (1) Interstitial fibrosis of $\mathrm{N}$ linear type, which criss-crosses over the affected 0 area and shows relatively little shrinkage. The intervening lung may be rendered more translucent $c$ by the formation of bullae, but rarely the picture is obscured by dense, fibrous thickening of the $\vec{A}$ parietal pleura. (2) Gummatous, appearing radio- $f$ logically as a tumour, though fibrous strands and ${ }^{N}$ emphysema in the surrounding lung provide differentiating features. (3) Pneumonic or atelectatic, and is nearly always confined to infants with congenital syphilis. (4) Glandular, which is due to\% enlargement of the bronchial glands.

It is in conjunction with antisyphilitic treatment $\overrightarrow{\overrightarrow{0}}$ that serial radiographs are most valuable. Gum- 3 mata show resolution under treatment, whereas dense sclerosis is radiologically unaffected. Funk (1920) has pointed out that tuberculosis may remain stationary on iodides, but is never improved, and usually made worse. Hartung and Freedman have warned that non-syphilitic spirochaetal infections clear readily on arsenical drugs; this serves as ai reminder that the therapeutic test must be inter- $\frac{3}{3}$ preted in the light of other data, clinical and serological. Messina (1943) records an interesting case of resistant lobar pneumonia in a luetic patient which cleared rapidly on antisyphilitic treatment.

The Wassermann Reaction.-The frequent association of syphilis with pulmonary tuberculosis 0 has been remarked by many authors. Allison (1929), $\omega$ after deploring the frequency with which lung syphilis was diagnosed on the basis of a suggestiveo radiograph and a positive Wassermann reaction, $\mathbb{\Phi}$ disclosed that statistics from various sanatoria ${ }^{+}$ showed an incidence of from 4 to $9 \%$ of positive W.R.s in individuals with definite uncomplicated, $\stackrel{+}{\mathbb{D}}$ sputum-positive tuberculosis. Denman (1932) found that at the Kings County Hospital, Brooklyn, $\stackrel{\mathbb{Q}}{\mathrm{Q}}$ between 1923 and 1926, of 191 patients with syphilis, $\mathcal{Q}$ no less than $26(15 \%)$ also had pulmonary tuber- 0 culosis. Lisser gives this appraisal: "The Wasser-0응 
mann test is helpful, if positive, in directing attention to the idea that the pulmonary lesion may be luetic, but merely signifies that the patient has lues; if negative, it has no value one way or another."

Diagnosis. - In the face of conflicting opinion, from the cautious pathologist who counts himself lucky to see one or two cases in a lifetime, to the enthusiastic (if misguided) radiologist who makes the diagnosis 172 times in the course of a few years, it is difficult to formulate diagnostic standards. Lists of clinical, radiological, and pathological criteria have been compiled by Howard, by Tylecote, and by Pearson and De Navasquez, but there is not one, including all of the laboratory criteria, that has not been criticized as fallacious under certain circumstances. But there can be no good reason for believing, as some diehards still do, that simply on account of its rarity and difficulty of proof syphilis cannot attack the lungs as well as any other organ. At least it appears safe to say that in a patient with a suggestive clinical picture, positive serological tests, and a persistently negative sputum for tubercle bacilli, if the radiological lesion clears decisively under antisyphilitic treatment, there are reasonable grounds for diagnosing pulmonary syphilis. And if, as the result of lobectomy or necropsy, typical gummata are demonstrated in the lung, then the diagnosis is virtually certain.

Treatment.-As a therapeutic test O'Leary and Ockuly (1945) recommend intramuscular injections of bismuth for two or three weeks, accompanied by potassium iodide thrice daily and " mapharsen" $0.01-0.06 \mathrm{mg}$. at five-day intervals for 10 to 12 injections. If improvement is satisfactory, treatment should be continued as in other forms of visceral syphilis. A case recorded by Kulchar and Windholz (1947) was successfully treated by penicillin.

If the patient fails to respond rapidly, the possibility of neoplasm must be reconsidered, and exploratory thoracotomy or lobectomy may be necessary (Bradley, 1948). If the gummata have permanently damaged the lung, it may be liable to haemorrhage, secondary infection or bronchiectasis, and lobectomy or segmental lobectomy may be advisable (Findlay and others, 1949).

\section{SUMmARY}

A case of tertiary syphilis of the lung is described. The diagnosis of pulmonary syphilis is difficult to establish, and the various clinical, radiological, and pathological criteria are discussed. The pathology of pulmonary syphilis is reviewed. It is concluded that the gumma is the only specific histological criterion.

Our thanks are due to our Medical Photography Department for assistance with the photomicrographs, and to the $X$-ray Department, Westminster Hospital, for permission to reproduce Fig. 1.

\section{REFERENCES}

Aguilar, O. P., and Bancalari, C. A. (1941). Arch. argent. Tisiol., 17,464

Allison, R. G. (1929). Amer. J. Roentgenol., 22, 21.

Bradley, D. F. (1948). Arch. Derm. Syph., Chicago, 58, 444

Carrera, J. L. (1920). Amer. J. Syph., 4, 1.

Denman, H. C. (1932). Ann. intern. Med., 5, 895

Dieulafoy, G. (1910). A Textbook of Medicine. Trans. V. E. Collins and J. A. Liebmann, vol. 1, p. 231.

Findlay, C. W., Lehman, W. L., and Rottenberg, L. A. (1949). Ann. Surg., 129, 274.

Finochietto, R., and Halperin, A. (1941). Semana méd., B. Aires, 48 (2), 1509

Funk, E. H. (1919-20). Amer. Rev. Tuberc.. 3, 754

Golden, R. (1921). Amer. J. Roentgenol., 8, 502.

Hartung, A., and Freedman, J. (1932). J.Amer. md. Ass., 98, 1969.

Howard, C. P. (1924). Amer. J. Syph., 8, 1.

Hu, C. K., Frazier, C. N., and Hsieh, C. K. (1939). Chin. med. J., 56, 431 .

Karshner, R. G., and Karshner, C. F. (1920). Ann. Med., Hagerstown, 1,371 .

Keilty, R. A. (1916). N.Y. med. J., 104, 252.

Koch, M. (1907). Verh. Dtsch. path. Ges., 11, 275.

Kulchar, G. V., and Windholz, F. (1947). Amer. J. Syph., 31, 166

Lisser, H. (1918). Amer. J. med.'Sci., 155, 356.

Lord, F. T. (1925). Diseases of the Bronchi, Lungs and Pleura, 2nd ed., p. 511. London.

McIntyre, M. C. (1931). Arch. Path. Chicago, 11, 258.

Messina, M. C. (1943). Med. Bull. Veterans' Adm., 20, 36

Navasquez, S. De (1942). J. Path. Bact., 54, 315.

Navasquez, S. De (1942). J. Path. Bact., 54, 315.
O'Leary, P. A., and Ockuly, O. E. (1945). J.-Lincet, 65, 154.

Pearson, R. S. B., and De Navasquez, S. (1938). Guy's Hosp. Rep., 88,1

Powell, R. D., and Hartley, P. H. (1911). On Diseases of the Lungs and Pleurae, 5 th ed., p. 338. London.

Robinson, W. W. (1935). Radiology, 25, 596.

Schmorl, G. (1907). Verh. Dtsch. path. Ges., 11, 281.

Stanley, J. D. (1911). Brit. med. J., 2, 802.

Symmers, D. (1916). J. Amer. med. Ass., 66, 1457.

Twining, E. W., and Kerley, P. (1951). In Shanks, S. C., and Kerley, P. (ed.), A. Textbook of X-ray Diagnosis, 2nd ed., vol. 2, p. 430. London.

Tylecote, F. E. (1927). Lancet, 2, 637.

Warthin, A. S. (1917). Amer. J. Syph., 1, 693.

Watkins, W. W. (1917). Ibid., 1, 760.

(1921). Amer. J. Roentgenol., 8, 259.

Wilson, J. M. (1946). Ann. intern. Med., 25, 134. 